\title{
Simulation and Analysis of Suspension System of Formula-1 Vehicle under Dynamic Conditions by using CAD Tools
}

\author{
K. Kishore Kumar', A. Srinath², K. Someswara Rao', K. G. V. Jayaram' and G. Syam Gopal' \\ 'Department of Mechanical Engineering, K. L. University, Green Fields, Vaddeswaram, Guntur - 522502, \\ AndhraPradesh, India; kishorekumardavid@kluniversity.in, someswararao@kluniversity.in, \\ kgvjayaram@gmail.com, syamgopal.g@gmail.com \\ ${ }^{2}$ NOVA College of Engineering and Technology, Jupudi, Ibrahimpatnam, Vijayawada - 541456, Andhra Pradesh, \\ India; srinath1879@gmail.com
}

\begin{abstract}
Objectives: To simulate and analyse the suspension system of formula- 1 car under dynamic condition by using solid works, hyper mesh and Adams software tools. Methods/Statistical Analysis: The method followed for modelling of front and rear suspension in Solid works by considering the vehicle components allowances and constraints, by decision matrix finalized the material for suspension components. The thickness and outer dimensions are reduced for the weight reduction, for the better performance in acceleration. By using Finite element analysis with Hyper mesh software and fined the deformations and stresses. Finally, simulation is performed in ADAMS to visualize working model. Findings: Deformations and stresses were found by using Finite element analysis with Hyper mesh software. Simulation is performed in ADAMS to visualize working model. Application/Improvements: Effective suspension system for formula-1 car. Through FEA reduced the material.
\end{abstract}

Keywords: Adams, Dynamic Condition, Hyper Mesh, Simulation, Solid Works, Suspension System

\section{Introduction}

The design of the automobile vehicle ${ }^{1}$ should satisfy the comfort and smooth adaptation on the road conditions. To satisfy theses requirement, the suspension system plays an important role. The passive suspension system has springs and dampers. The active suspension $\frac{1,2}{2}$ systems has actuators, springs and dampers.

Selection of Material: It is the most important part of the entire design process. Selection of material for the sport cars is very important hence the material for the fabrication has to be decided in according with the final requirement. The material must be of less weight and more strong for the sports car. Therefore, the suitable suspension material selected is chromoly by the following analysis.

\subsection{Decision Matrix for Material}

The decision matrix is written in order to select the material among the various different available materials. The parameters involved in matrix are cost, density, availability, yield strength, bending strength etc. The following material matrix is made for $\mathbf{1}$ (inch) $\mathbf{x} 0.095$ (inch). The Table 1 shows various parameters of Chromoly 4130, 1018 Steel, and T6 6061 Aluminium for finalizing selection of suitable material. 
Table 1. Representing various parameters of different materials

\begin{tabular}{|l|c|c|c|}
\hline Parameters & $\begin{array}{c}\text { Chromoly } \\
\mathbf{4 1 3 0}\end{array}$ & 1018 Steel & $\begin{array}{c}\text { T6 6061 } \\
\text { Aluminum }\end{array}$ \\
\hline $\begin{array}{l}\text { Yield strength } \\
\text { (ksi) }\end{array}$ & $\mathbf{6 3 . 1}$ & 53.7 & 40 \\
\hline $\begin{array}{l}\text { Bending } \\
\text { stiffness(lb x } \\
\left.\text { in }^{2}\right)\end{array}$ & $\mathbf{8 2 9 8 9 8 . 2 6 4 5}$ & 829898.2645 & 279430 \\
\hline $\begin{array}{l}\text { Bending } \\
\text { strength }(\mathrm{lb} x \\
\text { in) 2 }\end{array}$ & $\mathbf{3 5 2 6 . 3 6 9 0 5 7}$ & 3001.07 & 2237.13 \\
\hline Density $\left(\mathrm{lb} / \mathrm{in}^{3}\right)$ & $\mathbf{0 . 2 8 4}$ & 0.284 & 0.0975 \\
\hline Cost per Feet & $\mathbf{1 6 2 ~ I N R / f t . ~}$ & $60 \mathrm{INR} / \mathrm{ft}$. & $200 \mathrm{INR} / \mathrm{ft}$. \\
\hline
\end{tabular}

\subsection{Rating Matrix}

The rating matrix consists of points awarded to various parameters for the each selected materials. Table 2 shows the detailed ratings of each parameter of different type of material selected. The total rating for every material is given over 25. Chromoly is awarded with 21 points and is selected as the better material for the fabrication of the suspension.

Table 2. Representing rating given for different materials

\begin{tabular}{|l|c|c|c|}
\hline Parameters & $\begin{array}{c}\text { Chromoly } \\
\mathbf{4 1 3 0}\end{array}$ & $\begin{array}{c}\mathbf{1 0 1 8} \\
\text { steel }\end{array}$ & $\begin{array}{c}\text { T6 6-6061 } \\
\text { Aluminium }\end{array}$ \\
\hline Yield strength & $\mathbf{5}$ & 4 & 3 \\
\hline Manufacturability & $\mathbf{5}$ & 5 & 4 \\
\hline Bending strength & $\mathbf{5}$ & 4 & 2 \\
\hline weight & $\mathbf{3}$ & 3 & 5 \\
\hline cost & $\mathbf{3}$ & 5 & 2 \\
\hline Total & $\mathbf{2 1}$ & 20 & 15 \\
\hline
\end{tabular}

The materials which are used for different components of suspension are

- Aluminium is selected as the material for the rocker arm.

- Mild steel is selected for the Push rod.

- Chrome steel is selected for springs.

- Aluminium is selected for Caps.

- Adjustable columns are made up with aluminium.

\subsection{Material Selection Process}

Chromoly is selected as the material for the fabrication of A-Arms of suspension. To determine the outer diameter and thickness of the selected material, it is required to find the bending stiffness of the material at various thicknesses and at variable cross sections. The material with high bending stiffness is selected as the fabrication material. The below Figure 1 shows that the bending stiffness for chromoly 4130 at various cross sections with varying thickness.

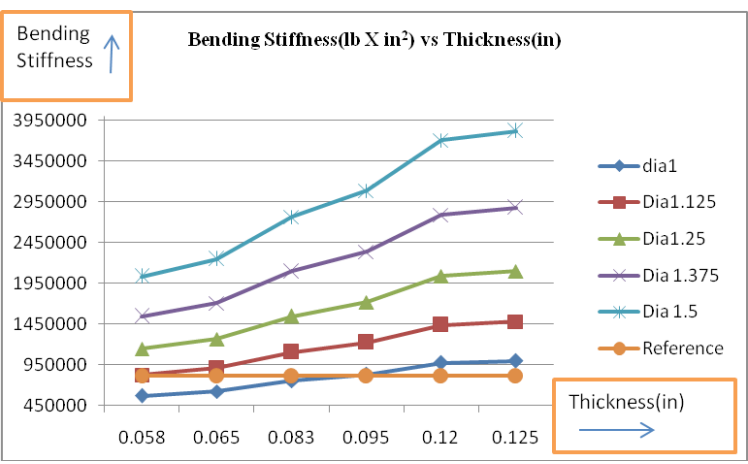

Figure 1. Graph between bending stiffness to thickness.

The Figure 2 shows that bending strength of chromoly 4130 at different thickness and variable diameters. Bending strength is high for thickness of $0.125 \mathrm{in}$.

The graph represents density of chromoly 4130 at variable thickness at various diameters. Analysing the three graphs are shown in Figure 1, Figure 2 and Figure 3. Chromoly 4130 is best suitable material with outer diameter of 1inch and thickness of 0.05 inch.

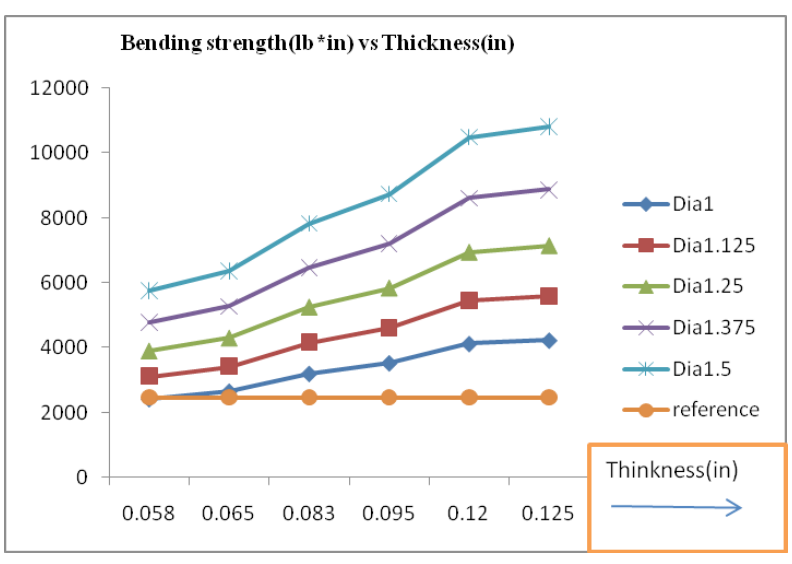

Figure 2. Graph between bending strength to thickness 


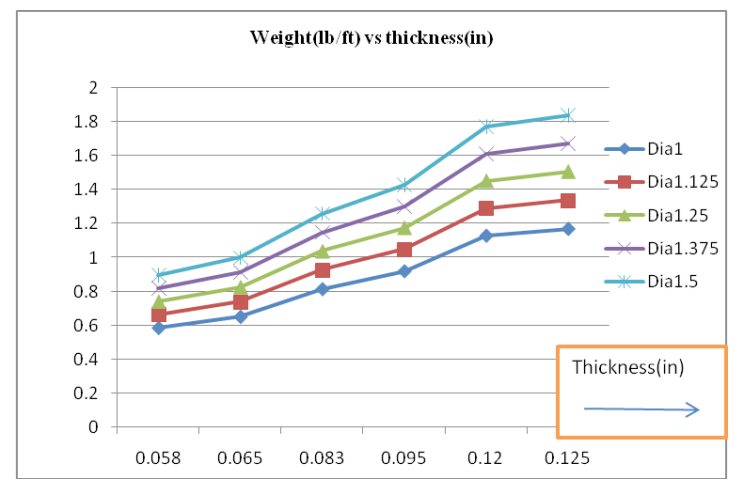

Figure 3. Graph between weights to thickness.

\section{Modelling in SOLIDWORKS}

After determining the wheel base and track width of the vehicle, chassis design is made according to the high strength and less weight. The complete design of vehicle in solid works is shown in Figure 4.

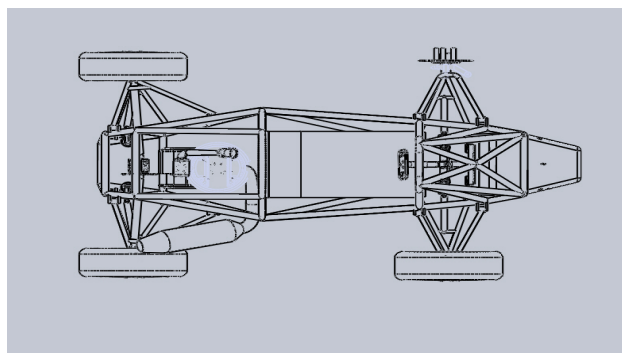

Figure 4. Top view of the Car.

\subsection{Rear Suspension Mounting}

The rear suspension is mounted in such a way most of the space is provided to engine, fuel tank and battery. Figure 5 shows the design of rear suspension in solid works and Figure 6 shows the top view of rear suspension system. The care is taken so that no part of the suspension can hit the chassis frame. The shaft travel is minimized to 4 inches.

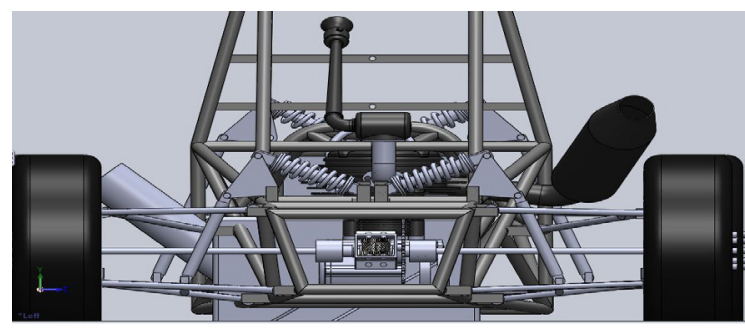

Figure 5. Rear suspension assembly in solid works.

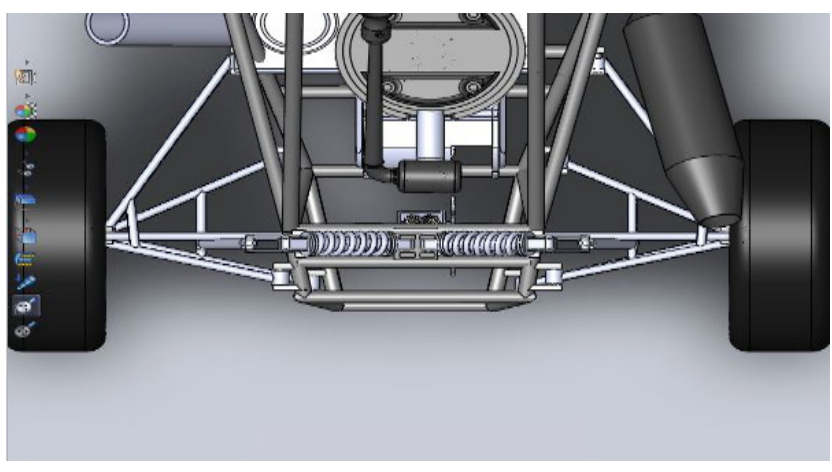

Figure 6. Top view of rear suspension.

\subsection{Front Suspension Mounting}

The front suspension is designed in such a way that it can accommodate space for steering, brakes and rider cabin. Figure 7 and Figure 8 show the detailed solid works designs of front suspension mountings. More care is also taken so that design is aesthetic.

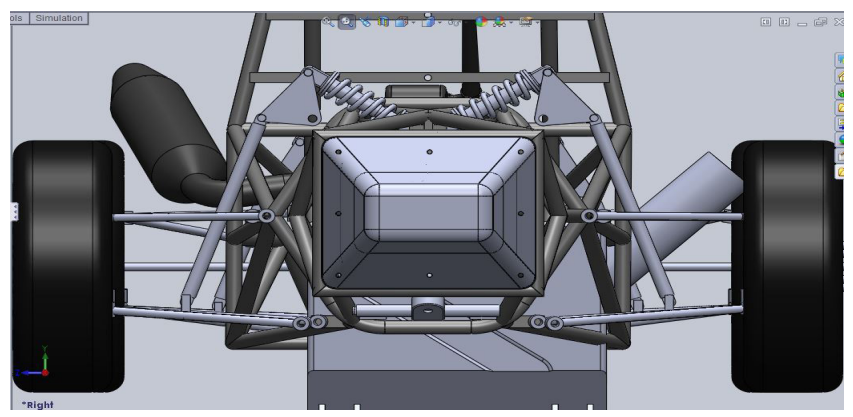

Figure 7. Front view of suspension mounting.

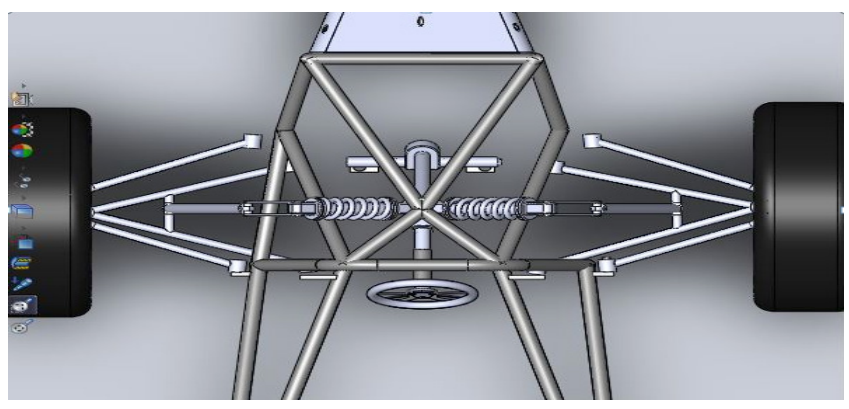

Figure 8. Top view of front suspension. 


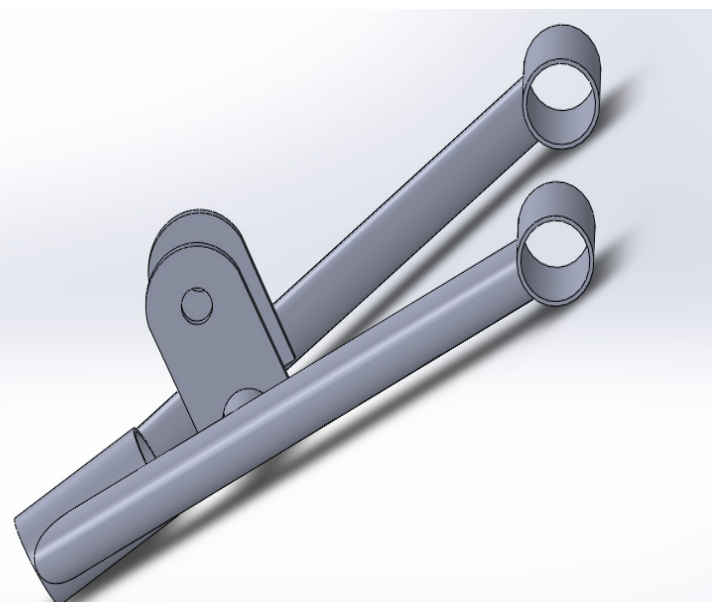

Figure 9. Upper arm of front suspension.

\section{Suspension Parts}

The main parts of suspension systems are A-arm, Push rods, Bracket, rocker arm

\subsection{A-Arm}

In automotive suspension, an automobile's control arm or wishbone (A-arm or A-frame) is a nearly flat and roughly triangular suspension member (or sub-frame), that pivots in two places. The base of the triangle attaches at the frame and pivots on a bushing ${ }^{3}$. The narrow end attaches to the steering knuckle and pivots on a ball joint. A control arm differs from a suspension link because it can control two degrees of freedom by itself. Figure 9 and Figure 10 show the solid works designs of upper arm of front and rear suspension assembly. The length of arm and distance between to mounting points is determined according to the flexibility of the designer.

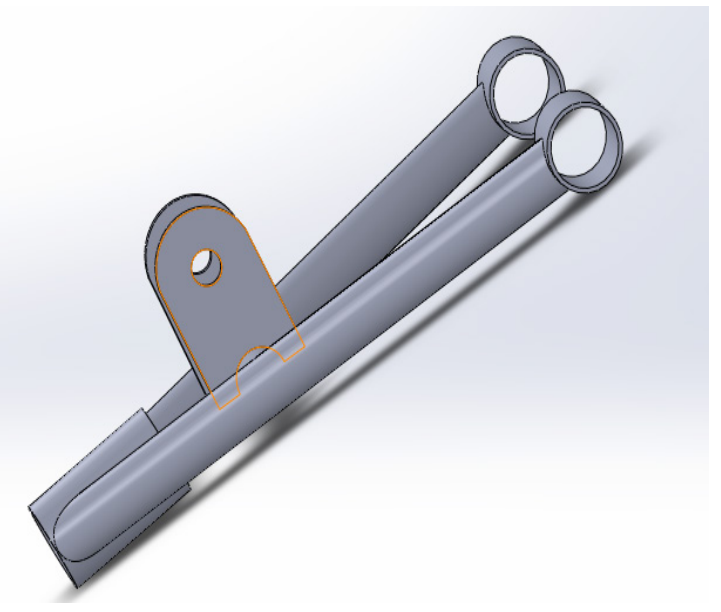

Figure 10. Upper arm of the rear suspension.

\subsection{Pushrod}

Pushrod is an important component of the suspension system. Figure 11 show the pushrod designed with the required dimensions. The force that is acting on the wheel is transmitted to spring through the push rod only. So, pushrod is supposed to be under the buckling load ${ }^{4}$. The material selected for the pushrod is mild steel. The mild steel rod with diameter $15 \mathrm{~mm}$ with length of $300 \mathrm{~mm}$ Pushrod is assembled to the vehicle with the help of rod end bearings.

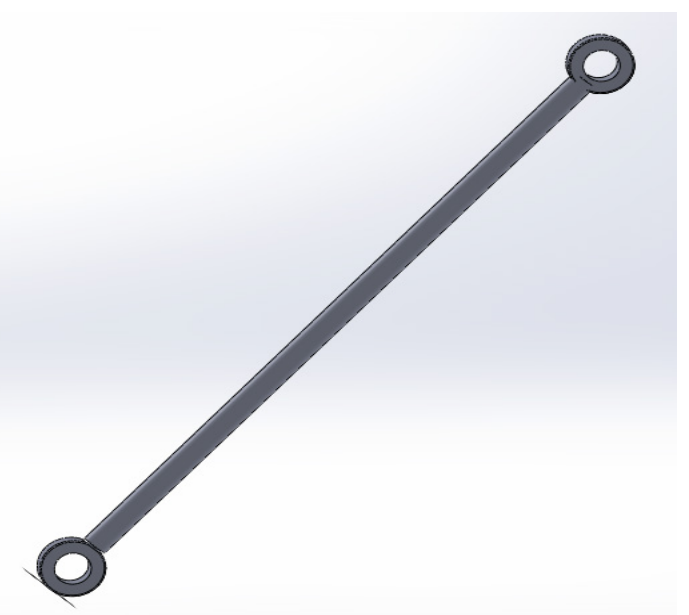

Figure 11. Pushrod design.

\subsection{Rocker Arm}

The motion is transmitted to the spring from push rod to spring through the rocker arm. This rocker arm will be mostly a triangular element. Figure 12 shows the rocker arm design.

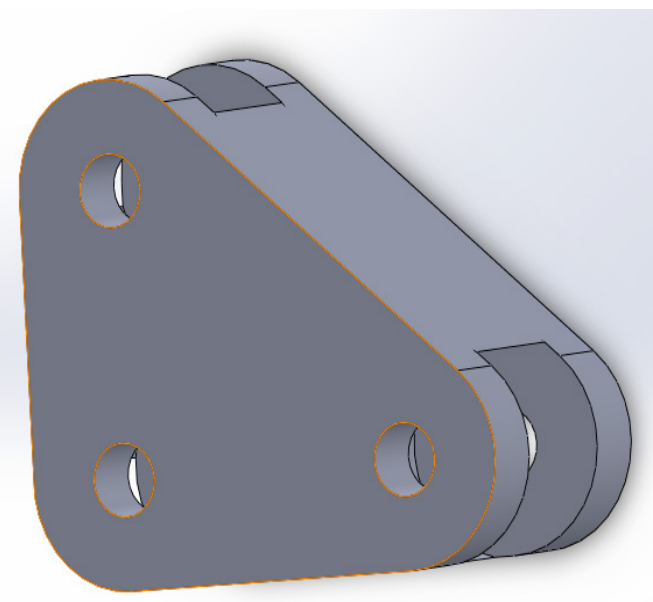

Figure 12. Rocker arm design. 


\subsection{Bracket}

The brackets are the mounts of A-Arms, rocker arm and also pushrod. The weight of vehicle is finally based on to the brackets 5 . The Figure 13 shows bracket designed in solid works. There will be totally more than 48 brackets in the suspension assembly.

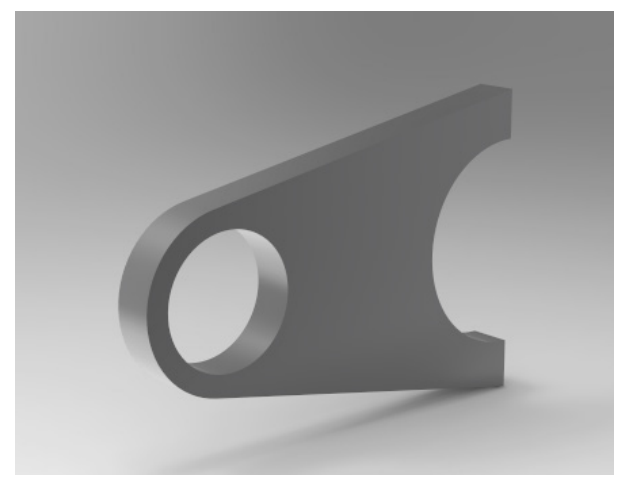

Figure 13. Bracket.

\section{Analysis in Hyper Mesh}

Hypermesh is a great tool used for analysis of the objects, the analysis of A-Arm, pushrod, rocker arm and bracket is done. The force value is taken from the lotus for each join and load on the individual parts were found out.

\subsection{Analysis of A-Arms}

The analysis is made on the front upper arm for the front suspension and upper arm for the rear suspension. Figure 14, Figure 15, Figure 16 and Figure 17 show the detailed displacement and Stress analysis of front and rear A-arm in Hyper mesh. The force applied on the A-Arms is $2 \mathrm{~g}$ force and value of the forces is $1780 \mathrm{~N}$.

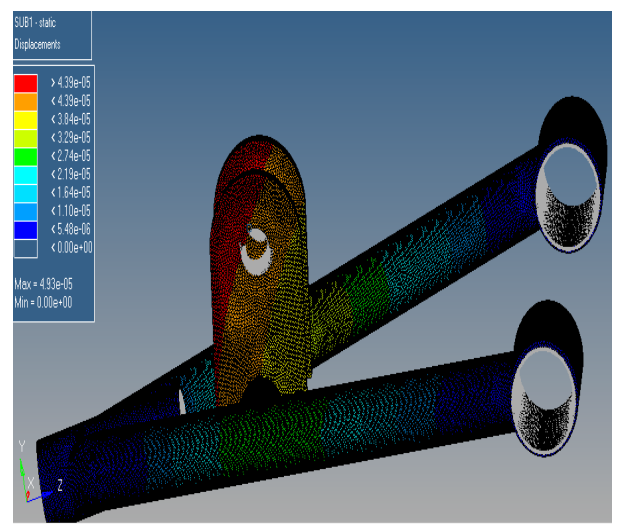

Figure 14. Displacements of the Front A-Arm.

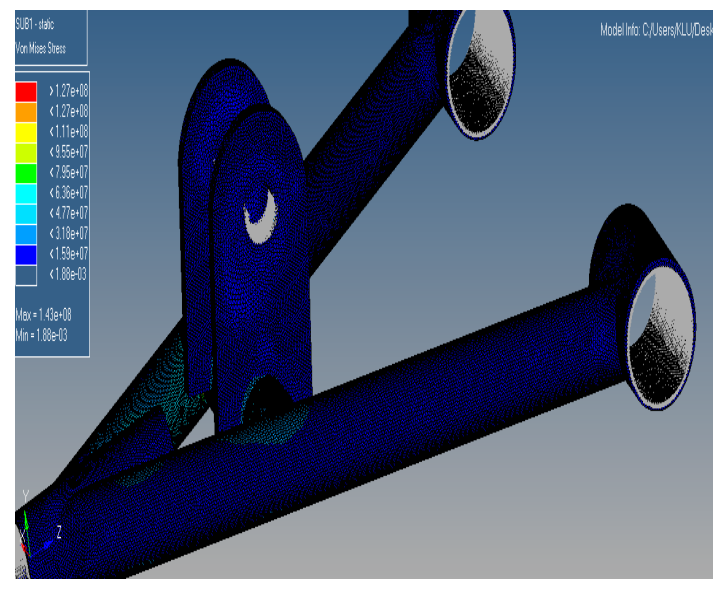

Figure 15. Stresses of front A-Arm.

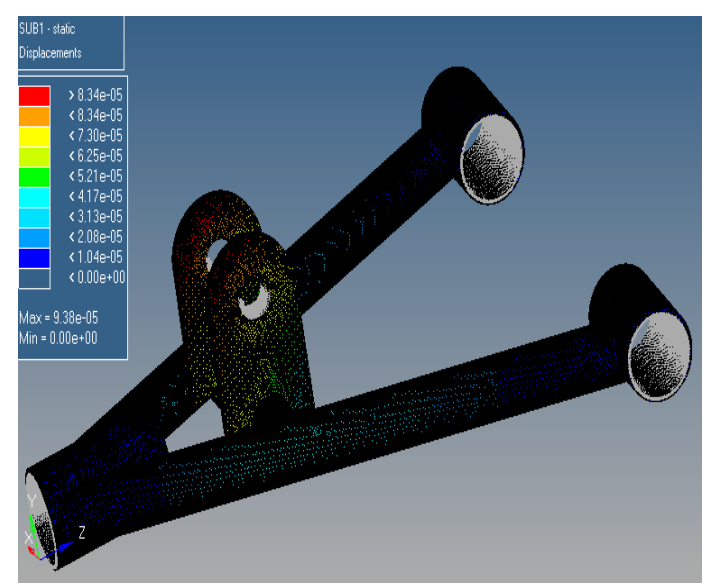

Figure 16. Displacements of rear A-Arm.

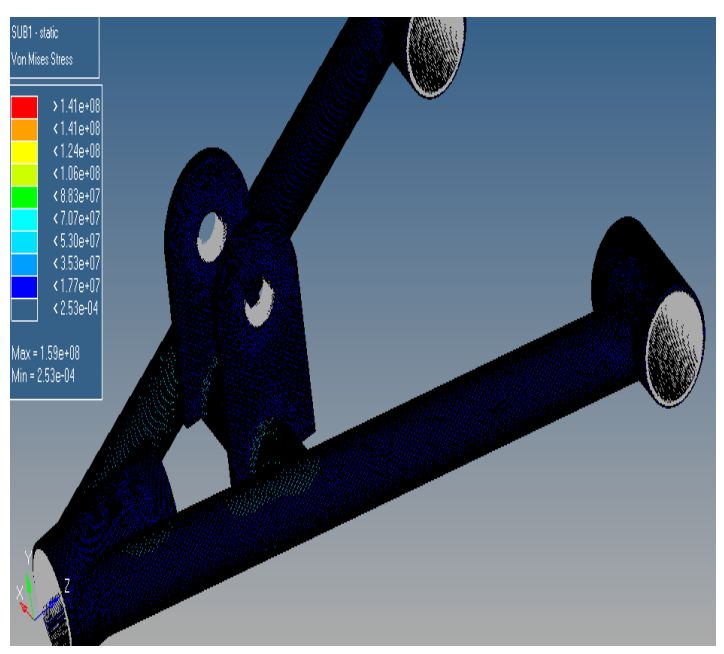

Figure 17. Stresses in rear A-Arm. 


\subsection{Analysis on Pushrod}

Buckling analysis is made on the pushrod by resting the one end and applying the force on the other end of the rod. Figure 18 shows the stress analysis on pushrod.

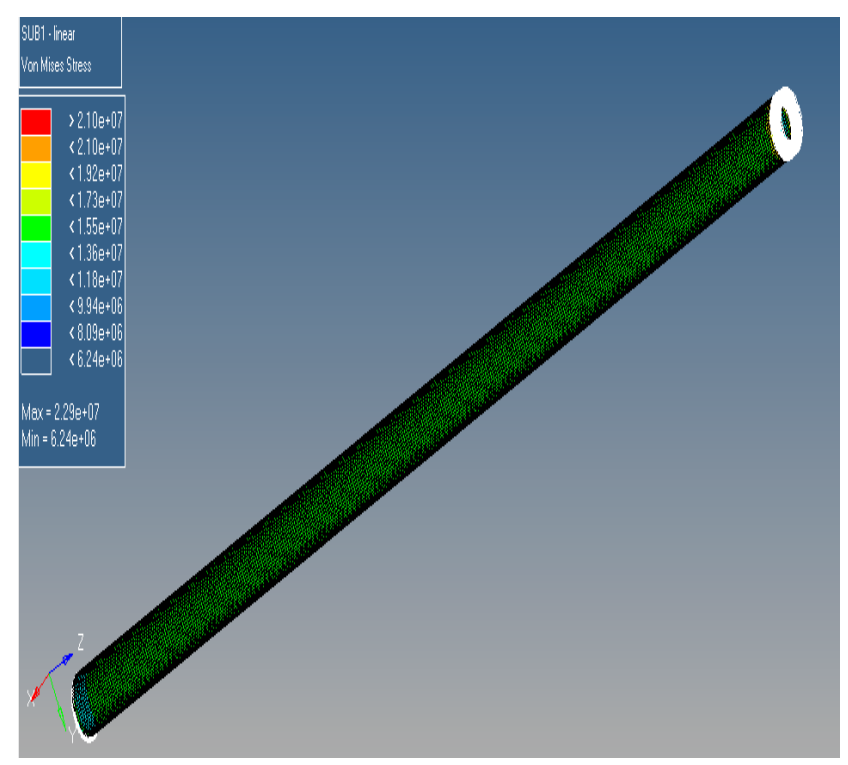

Figure 18. Analysis of stress on pushrod.

\subsection{Analysis on Bracket}

Point load is applied on the bracket in the direction of the application of the force. Figure 19 show the stress analysis of bracket.

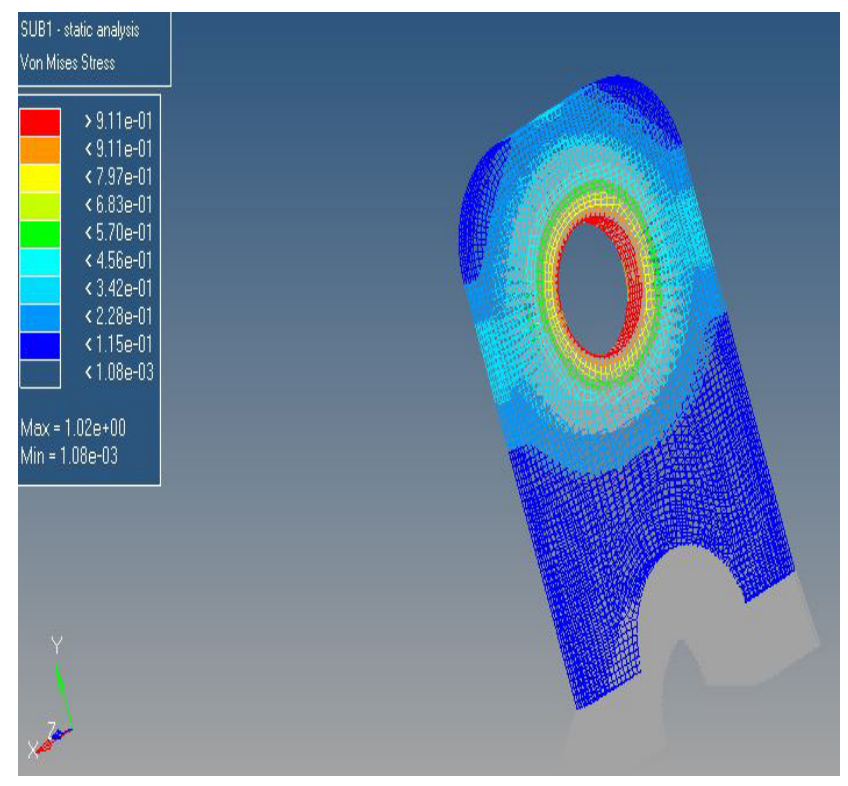

Figure 19. Stress analysis on bracket.

\subsection{Analysis on Rocker Arm}

The chassis point is grounded and moment is applied on the remaining two holes. The stress analysis on rocker arm is shown in Figure 20.

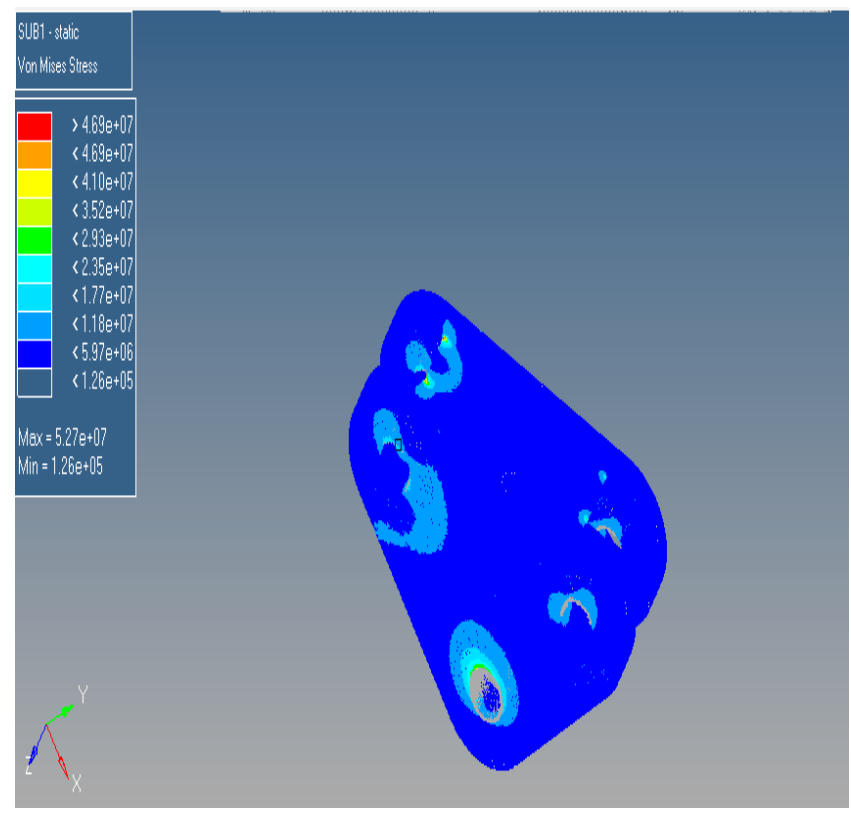

Figure 20. Stress analysis on rocker arm.

The Table 3 shows summary of displacements, stress and Factor of safety values of different components.

\section{Analysis by using ADAMS}

ADAMS is used for multibody dynamic simulation to know the movement of a body with respect to the others and also forces in multi links.

Adams is used to find the force outputs in the different joints of the suspension system. Figure 21 shows the simulated model in Adams. The maximum force on the suspension system is found as $2000 \mathrm{~N}$ at maximum spring deformation of 70 $\mathrm{mm}$. The results were plotted over maximum force to the maximum spring deformation in time scale in two different graphs as shown in Figure 22 and Figure 23. 
Table 3. The displacements and stresses in parts

\begin{tabular}{|l|l|c|c|c|c|c|}
\hline s.no & Component & Value of load & $\begin{array}{c}\text { Maximum } \\
\text { displacement }\end{array}$ & $\begin{array}{c}\text { Minimum } \\
\text { displacement }\end{array}$ & $\begin{array}{c}\text { Maximum } \\
\text { stress(N/m2) }\end{array}$ & F.O.S \\
\hline 1 & Front A-Arm & $2 \mathrm{~g}$ & $4.90 \mathrm{e}-7 \mathrm{~m}$ & 0 & 1270 & 3.13 \\
\hline 2 & Rear A-Arm & $2 \mathrm{~g}$ & $3.98 \mathrm{e}-6 \mathrm{~m}$ & 0 & 1064 & 3.5 \\
\hline 3 & Pushrod & $2 \mathrm{~g}$ & $2.96 \mathrm{e}-8 \mathrm{~m}$ & 0 & 345 & 7.9 \\
\hline 4 & Bracket & $2 \mathrm{~g}$ & $3.89 \mathrm{e}-7 \mathrm{~m}$ & 0 & 458 & 6.4 \\
\hline 5 & Rocker arm & $2 \mathrm{~g}$ & $3.46 \mathrm{e}-7 \mathrm{~m}$ & 0 & 382 & 3.9 \\
\hline
\end{tabular}

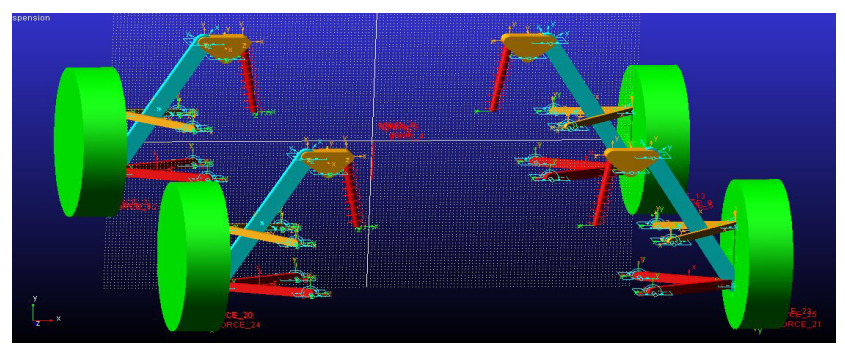

Figure 21. Simulation model of Front and Rear suspension in ADAMS.

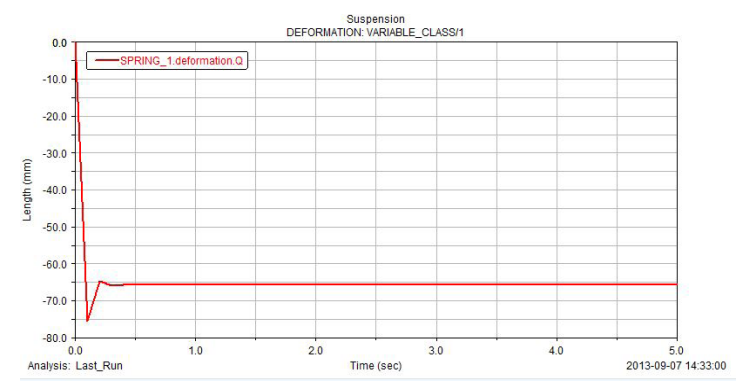

Figure 22. Graph drawn for time interval and spring travel.

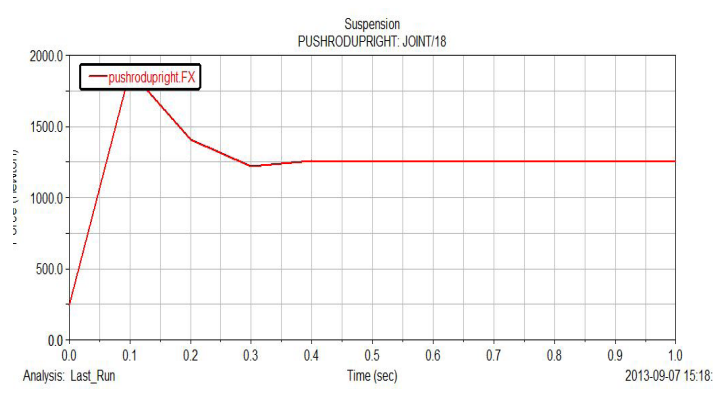

Figure 23. Graph drawn for the maximum force to time interval.

\section{Conclusions}

The simulated suspension results were perfect for the race car suspension system development. The suspension system was developed to the race car and tested it. The test evaluation was agreed perfect with the simulation models.

\section{References}

1. Kang HI, Kang HS. A Study on Performances of Passenger vehicle Suspension systems. Indian Journal of Science \& Technology. 2015 Jan; 8(s1):1-3.

2. Kalaivani R, Sudhagar K, Lakshmi P. Neural Network based Vibration Control for Vehicle Active Suspension System. Indian Journal of Science and Technology. 2016 Jan; 9(1):1-8.

3. Krithika V, Subramani C, Geetha A. Smart Adaptive Suspension System using MR Fluid. Indian Journal of Science and Technology. 2016 Jul; 9(28):1-6.

4. Trikande MW, Rajamohan V. MR Damper Characterization for Implementation of Semi-active Suspension Control. Indian Journal of Science and Technology. 2016 Aug; 9(30):1-11.

5. Amin AZM, Ahmad S, Hoe YS. Electromagnetics Car Suspension System. Indian Journal of Science and Technology. 2016 Oct; 9(40):1-4. 